\title{
Design Improvement and Vibration Analysis of Gantry System using Finite Element Method (FEM)
}

\author{
Faris A. Putra \\ Department of Mechanical Engineering \\ Swiss German University \\ Tangerang 15143, Indonesia \\ Email: aris.aditya.p@gmail.com
}

\author{
Dena Hendriana \\ Department of Mechanical Engineering \\ Swiss German University \\ Tangerang 15143, Indonesia
}

\author{
Hanny J. Berchmans \\ Department of Mechanical Engineering \\ Swiss German University \\ Tangerang 15143, Indonesia
}

\begin{abstract}
A Gantry or linear robot is an industrial robot that move in straight line in three axes and at right angles to each other. Its structure must be able to hold the vibration depends on its function because vibration behaviour and natural frequency plays a key role to every system in dynamic analysis, which can cause the system failure. Finite Element Method (FEM) and gyroscope can be used to analyze the vibration and natural frequency, it is very important to improve the design to avoid system failure. Gantry system in PT. Akebono Brake Astra Indonesia has un-rigid structure and contain too much vibration. The system was designed in 3D CAD by Solidworks software and analyzed using frequency analysis, then comparing the result with experimental result using accelerometer gyroscope to know the validity of the model. Design improvement is conducted to improve the vibration system by increasing their natural frequency. From the improvement result, the natural frequency increased in every mode shape, mode 1: from 16,559 $\mathrm{Hz}$ become $23,56 \mathrm{~Hz}$; mode 2 : from $17,903 \mathrm{~Hz}$ become 30,967 $\mathrm{Hz}$; mode 3: from $55,856 \mathrm{~Hz}$ become $60,715 \mathrm{~Hz}$; mode 4: from $73,804 \mathrm{~Hz}$ become 82,266 $\mathrm{Hz}$; mode 5 : from $88,367 \mathrm{~Hz}$ become $97,477 \mathrm{~Hz}$.
\end{abstract}

Keywords: Gantry, Vibration, Natural Frequency, Mode Shape, Finite Element Method.

\section{INTRODUCTION}

A Gantry or linear robot (also known Cartesian coordinate robot) is an industrial robot that move in straight line rather than rotate in three axes and at right angles to each other. The wrist with three sliding joints can move back-forth, inout, and up-down. This mechanical system is to simplifies the robot arm system, and in the end of the wrist can be combined with gripper, magnet, vacuum, and etc. In industrial, the gantry system usually use for pick and place, CNC Machines, and $3 \mathrm{D}$ printing. Every structure must be able to hold the load and vibration depends on its function. Once a structure design finished, the strength and stiffness must be analyzed to ensure that it is fulfill the requirements. To analyze the structure, it should be given a load and vibration in certain locations so the displacement and frequency will be found used structural analysis theory. The structure can be redesigned to determine the weight and the size of each members depends on the analysis result [5].

Design is very important to make a product, it is the main aspect to make World-Competitive Product. High Quality Product design will have three major impacts on the product result. The first major impact of design is on manufactured cost of the product, easier the product to be made, so the manufacture process will be cheaper and it will reduce the cost of product. The second major impact of design is on product quality, it determines the durability and the function of the product itself in the best performace or not. The product can be made without defect, so it can avoid unnecessary cost. The last major impact is on product cycle time, it affect on process time required to produce a new product, reduce Man Hour, and reduce over time cost. The longer a product is available for sale, the faster can fulfill customers order, the more sales and profits there will be [4].

Finite Element Methods is a numerical procedure that is widely used to overcome computer-based problems or techniques to do an analysis in engineering design and used to complete the process of Computer-Aided Design (CAD). The study of MEH has developed very rapidly and has become a necessity for the scientific world now which can be widely used. In the beginning, FEM analyze the mechanical structure, but now it can be used to analyze heat transfer, fluid flows, and vibration [2].

\section{LITERATURE REVIEW}

The frame structure is very important thing for every system, it is the key to get the best quality, durability, and safety of the system. The frame structure is the place where every components of a system placed, so it must be able to accept all types of loading and vibration that occurs. The frame structure has variety of responses to vibration, to find out the response can be done in some ways, use Finite Element Method (FEM) simulation softwares and data acquisition using gyroscope.

\section{A. Solidworks}

One of the most important method in technology research and science are modelling process and simulation. Solidworks is a parasolid based modelling software and uses a parametric feature based to make assemblies and models. The Solidworks simulation allow the designers to verify the strength and safety of assemblies or models. The Solidworks simulation has provided features that allow to using Finite Element Method 
(FEM), so it can simulate stress and strain of structures, flow of fluid, heat, fatigue, vibration, and others [6].

\section{B. Accelerometer Gyroscope}

An accelerometer gyroscope is a device or sensor made from spinning disc or wheel mechanism to measure and maintain orientation that harnesses the principle of momentum. The orientation will changes in response to an external torque and different direction, and it would cooperate with high rate of spin and inertia of the disc without the large angular momentum. Since the gyroscope can calculate the rotation and orientation, designers has developed it into modern technology. The gyroscope can integrate more accurate recognition of movement within a 3D Space, it combined with accelerometer for more robust direction and motion sensing. Applications of gyroscope are navigation system, virtual reality, and smartphone [12].

Accelerometer Gyroscope which will be used is The MPU6050 GY-521, its contains 16-bits analog to digital conversion and include an accelerometer and a gyro in a single chip which make it accurate, it read the $\mathrm{x}, \mathrm{y}$, and $\mathrm{z}$ channel at the same time and uses the $\mathrm{I}^{2} \mathrm{C}$-bus to interface with the Arduino. The specification of Accelerometer Gyroscope:

- Use the chip: MPU-6050.

- Power supply: 3-5v (internal low dropout regulator).

- Communication modes: standard $\mathrm{I}^{2} \mathrm{C}$ communications protocol.

- Chip built-in 16bit AD converter, 16-bit data output.

- Immersion Gold PCB machine welding process to ensure quality.

- 3-Axis angular rate sensor (gyro) with a sensitivity up to $131 \mathrm{LSBs} / \mathrm{dps}$ and a full-scale range of $\pm 250, \pm 500$, \pm 1000 , and $\pm 2000 \mathrm{dps}$

- 3-Axis accelerometer with a programmable full scale range of $\pm 2 \mathrm{~g}, \pm 4 \mathrm{~g}, \pm 8 \mathrm{~g}$ and $\pm 16 \mathrm{~g}$

\section{Mode Shape}

Mode shape is a function defined over a structure which describes the relative displacement of any point on the structure as the structure vibrates in a single mode, every vibration have influence on the mode shapes. Every mode shape has its unique natural frequency, it means mode shape associated with each natural frequency of a structure. The measurement location of mode shape is the main concern, because there are areas with zero-displacement that sensor should not be placed on it [3].

\section{Validation}

Validation is very important to prove that the simulation which is being processed is correct. Simple model is enough to be simulated, and the result will be compared with theoretical calculation. The simplest model that can be analyzed is a beam, the boundary condition for the transverse vibration of a beam can be seen in Figure 1.

First of all, we must know the cross section area of a beam

$$
A=b \times h
$$

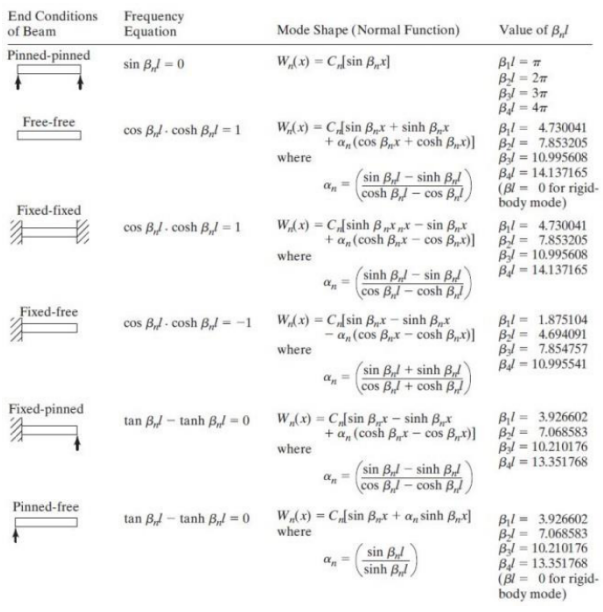

Fig. 1. Boundary condition for the transverse vibration of a beam.

. Second, after we get the cross section area value, the moment of inertia and mass of a beam can be known by

$$
\begin{aligned}
I & =b \times h^{3} \times 12^{-1} \\
m & =\rho \times A \times l
\end{aligned}
$$

Third, we can get the stiffness of a beam from the moment of inertia before

$$
k=E \times I \times l^{-3}
$$

Last, the natural frequency equation of a beam will become:

$$
\begin{aligned}
\omega_{n} & =\left(\beta_{n} \times l\right)^{2} \times\left(k \times m^{-1}\right)^{\frac{1}{2}} \\
f_{n} & =\omega_{n}(2 \pi)^{-1}
\end{aligned}
$$

where: $b=$ Cross section base $(\mathrm{m}), h=$ Cross section height (m), $l=$ Length of beam (m), $\rho=$ Density $\left(\mathrm{kg} / \mathrm{m}^{3}\right), A=$ Cross section area $\left(\mathrm{m}^{2}\right), I=$ Moment of Inertia $\left(\mathrm{m}^{4}\right), E=$ Modulus Young $\left(\mathrm{N} / \mathrm{m}^{2}\right), k=$ Stiffness $(\mathrm{N} / \mathrm{m}), \omega_{n}=$ Natural frequency $(\operatorname{Rad} / \mathrm{s}), f=$ Natural frequency $(\mathrm{Hz})$.

\section{E. Arduino}

The Arduino Mega2560 is a microcontroller board based on ATmega 2560, it has 54 digital input/output pins, 16 analog inputs, a $16 \mathrm{MHz}$ crystal oscillator, 4 UARTs, a power jack, a USB connection, an ICSP header, and a reset button. It is powered by the USB connection or external supply such as battery and adapter. The adapter can be connected into boards power jack by plugging a $2.1 \mathrm{~mm}$ center positive plug [1]. 
TABLE I

COMPARISON BETWEEN SIMULATION AND THEORETICAL CALCULATION IN FIRST DIMENSION

\begin{tabular}{|c|c|c|c|c|c|}
\hline $\begin{array}{l}\text { Dimension } \\
(\mathrm{b} \times \mathrm{h} \times \mathrm{l})\end{array}$ & Fixtures & $\begin{array}{l}\text { Mode } \\
\text { Shape }\end{array}$ & $\begin{array}{l}\text { Frequency } \\
\text { (Hz) By } \\
\text { Theoret- } \\
\text { ical }\end{array}$ & $\begin{array}{l}\text { Frequency } \\
(\mathrm{Hz}) \mathrm{By} \\
\text { Simula- } \\
\text { tion }\end{array}$ & Difference \\
\hline \multirow{8}{*}{$\begin{array}{l}0.01 \mathrm{~m} \mathrm{x} \\
0.01 \mathrm{~m} \mathrm{x} \\
1 \mathrm{~m}\end{array}$} & \multirow{5}{*}{$\begin{array}{l}\text { Fixed - } \\
\text { Free }\end{array}$} & Mode 1 & 8.439 & 8.439 & $0.00 \%$ \\
\hline & & Mode 2 & 52.886 & 52.864 & $0.04 \%$ \\
\hline & & Mode 3 & 148.083 & 147.910 & $0.12 \%$ \\
\hline & & Mode 4 & 290.184 & 289.530 & $0.23 \%$ \\
\hline & & Mode 1 & 53.669 & 53.694 & $-0.05 \%$ \\
\hline & \multirow{3}{*}{$\begin{array}{l}\text { Fixed - } \\
\text { Fixed }\end{array}$} & Mode 2 & 148.025 & 147.880 & $0.10 \%$ \\
\hline & & Mode 3 & 290.187 & 289.560 & $0.22 \%$ \\
\hline & & Mode 4 & 479.694 & 477.930 & $0.37 \%$ \\
\hline
\end{tabular}

\section{F. $P L X-D A Q$}

PLX-DAQ is an add-on software of Microsoft Excel, which has the function to export data from sensor that connect to any microcontrollers to excel, it can update the data in excel automatically based on the output of microcontrollers in realtime [13].

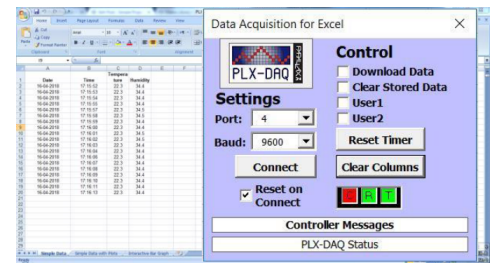

Fig. 2. PLX-DAQ connect with Microsoft excel.

\section{RESUlT AND DisCUSSION}

\section{A. Validation Result}

The validation of this research will compare the simulation result and theoretical result using simple model, in this case uses beam as a model. There are 2 simple model of beams with different dimensions, the first model is $(10 \times 10 \times 1000) \mathrm{mm}$ beam, and the second model is $(20 \times 20 \times 1000) \mathrm{mm}$ beam. Every model will be analyzed in 2 boundary condition, the first condition is fixed-free ends, and the second condition is fixedfixed ends. The material used by a beam is alloy steel, and its material properties are based on Solidworks data of material. Its Modulus Young $(E)=2,1 \times 1011 \mathrm{~N} / \mathrm{m}^{2}$ and density $(\rho)=$ $7.700 \mathrm{~kg} / \mathrm{m}^{3}$. From simulation and theoretical calculation with all models in all conditions, the difference value result can be compared in Table I.

The average difference between simulation and theoretical calculation is $0.51 \%$ caused by simplification of calculation method, it means that the simulation result with Solidworks software is valid.
TABLE II

COMPARISON BETWEEN SIMULATION AND THEORETICAL CALCULATION IN SECOND DIMENSION

\begin{tabular}{|c|c|c|c|c|c|}
\hline $\begin{array}{l}\text { Dimension } \\
(\mathrm{b} \times \mathrm{h} \times \mathrm{x})\end{array}$ & Fixtures & $\begin{array}{l}\text { Mode } \\
\text { Shape }\end{array}$ & $\begin{array}{l}\text { Frequency } \\
(\mathrm{Hz}) \text { By } \\
\text { Theoret- } \\
\text { ical }\end{array}$ & $\begin{array}{l}\text { Frequency } \\
(\mathrm{Hz}) \text { By } \\
\text { Simula- } \\
\text { tion }\end{array}$ & Difference \\
\hline \multirow{8}{*}{$\begin{array}{l}0.02 \mathrm{~m} \mathrm{x} \\
0.02 \mathrm{~m} \mathrm{x} \\
1 \mathrm{~m}\end{array}$} & \multirow{5}{*}{$\begin{array}{l}\text { Fixed - } \\
\text { Free }\end{array}$} & Mode 1 & 16.860 & 16.882 & $-0.13 \%$ \\
\hline & & Mode 2 & 105.657 & 105.600 & $0.05 \%$ \\
\hline & & Mode 3 & 295.842 & 284.810 & $3.73 \%$ \\
\hline & & Mode 4 & 579.733 & 575.240 & $0.78 \%$ \\
\hline & & Mode 1 & 107.280 & 107.260 & $0.02 \%$ \\
\hline & \multirow{3}{*}{$\begin{array}{l}\text { Fixed - } \\
\text { Fixed }\end{array}$} & Mode 2 & 295.730 & 294.630 & $0.37 \%$ \\
\hline & & Mode 3 & 579.740 & 574.910 & $0.83 \%$ \\
\hline & & Mode 4 & 958.340 & 944.800 & $1.41 \%$ \\
\hline
\end{tabular}

TABLE III

NATURAL FREQUENCY OF ACTUAL SYSTEM

\begin{tabular}{llll}
\hline $\begin{array}{l}\text { Mode } \\
\text { No. }\end{array}$ & $\begin{array}{l}\text { Frequency } \\
(\text { Rad/sec) }\end{array}$ & $\begin{array}{l}\text { Frequency } \\
\text { (Hertz) }\end{array}$ & $\begin{array}{l}\text { Period } \\
\text { (Seconds) }\end{array}$ \\
\hline 1 & 104.04 & 16.559 & 0.060391 \\
2 & 112.49 & 17.903 & 0.055855 \\
3 & 350.96 & 55.856 & 0.017903 \\
4 & 463.73 & 73.804 & 0.013549 \\
5 & 555.22 & 88.367 & 0.011316 \\
\hline
\end{tabular}

\section{B. Actual Design}

The system that will be analyzed in this research is only the arm of the gantry in PT. Akebono Brake Astra Indonesia, These are the actual design of the arm of gantry system:

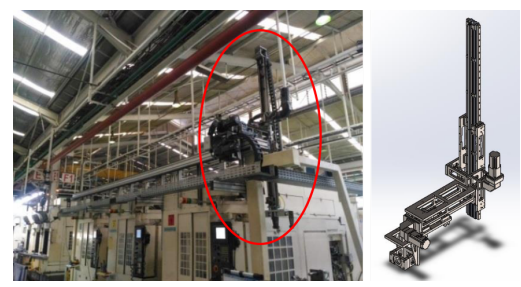

Fig. 3. Gantry system that will be analized and the 3D Design of gantry system.

\section{Simulation Result of Actual Design}

The output of this simulation are Natural frequency in 5 modes using Solidworks software. From the mode itself, which parts that need to be improved can be known based on the natural frequency. These simulation result of 5 Modes Shape can be seen in Table III.

Based on Table IV, there are conclusions that can be analyzed for further research: 1 . The lowest natural frequency of actual system is in first and second mode. 2. The highest amplitude in $\mathrm{x}$ direction located in the fifth mode. 3. The 
TABLE IV

AMPLITUDE OF ACTUAL SYSTEM

\begin{tabular}{lllll}
\hline Mode & X direction & Y direction & Z direction & Resultant \\
\hline 1 & $5.482 \mathrm{E}-02$ & $3.170 \mathrm{E}-03$ & $2.234 \mathrm{E}-02$ & $3.218 \mathrm{E}-01$ \\
2 & $1.769 \mathrm{E}-03$ & $3.840 \mathrm{E}-01$ & $4.136 \mathrm{E}-03$ & $3.847 \mathrm{E}-01$ \\
3 & $3.229 \mathrm{E}-02$ & $1.372 \mathrm{E}-01$ & $7.871 \mathrm{E}-02$ & $3.126 \mathrm{E}-01$ \\
4 & $1.596 \mathrm{E}-01$ & $1.473 \mathrm{E}-01$ & $1.758 \mathrm{E}-01$ & $2.653 \mathrm{E}-01$ \\
5 & $1.940 \mathrm{E}-01$ & $4.471 \mathrm{E}-02$ & $1.549 \mathrm{E}-02$ & $2.284 \mathrm{E}-01$
\end{tabular}

highest amplitude in y direction located in the second mode. 4. The highest amplitude in $\mathrm{z}$ direction located in the fourth mode. 5. The highest resultant amplitude located in the second mode. From conclusions above, it means the natural frequency in the first and second mode must be improved because the value is too low located on the top of gantry, and the amplitude from the first until sixth mode must be improved because the value is too high.

\section{Data acquisition of actual system}

Before improving the actual system to increase the natural frequency value, real data must be acquired with accelerometer gyroscope GY-521 sensor (Fig.4). The sensor will be placed in the place which has the highest resultant amplitude in first and second mode then connect to arduino and note book to do data acquisition. To get the amplitude data in real time and convert it to excel format, use PLX-DAQ software. Some program in arduino need to be modified, so the PLX-DAQ can transfer the data from arduino to excel. The data will be taken when the system running in one cycle, so the highest amplitude can be known in certain position.

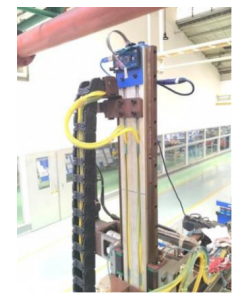

(a)

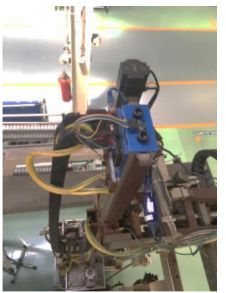

(b)
Fig. 4. (a) Arduino attached on the top of the arm of gantry. (b) Accelerometer Gyroscope attached on the top of the arm of gantry.

\section{E. Visualization in Matlab}

Data acquisition result must be converted to MATLAB software to get the value of frequency, then plot every $X$, $\mathrm{Y}$, and $\mathrm{Z}$ direction data using Window Visualization Tool (wvtool). The result of visualization in Matlab can be seen in Figure 5.

From visualization above, frequency result will be known in X, Y, and Z-direction. The comparison between simulation and experimental can be seen in Table V.

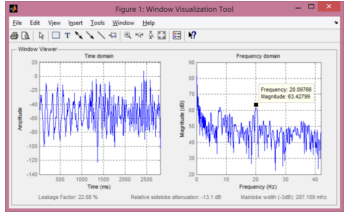

Fig. 5. Data acquisition visualization in Matlab.

TABLE V

COMPARISON OF SIMULATION AND EXPERIMENTAL RESULT.

\begin{tabular}{llllllll}
\hline Simulation Mode & \multicolumn{3}{c}{ Gyroscope } & \multicolumn{3}{c}{ Accelerometer } \\
\hline 1 & 2 & X & Y & Z & X & Y & Z \\
\hline $16,56 \mathrm{~Hz}$ & $17,9 \mathrm{~Hz}$ & $20,09 \mathrm{~Hz}$ & $20,09 \mathrm{~Hz}$ & $19,85 \mathrm{~Hz}$ & $20,18 \mathrm{~Hz}$ & $8,86 \mathrm{~Hz}$ & $20,18 \mathrm{~Hz}$ \\
\hline
\end{tabular}

Mode 1 is in the same direction with Y-direction and mode 2 is in the same direction with X-direction. The difference between simulation using solidworks software and experimental using accelerometer gyroscope result is about $3,53 \mathrm{~Hz}$ in $\mathrm{Y}$ direction, and 2,19 in X-direction.

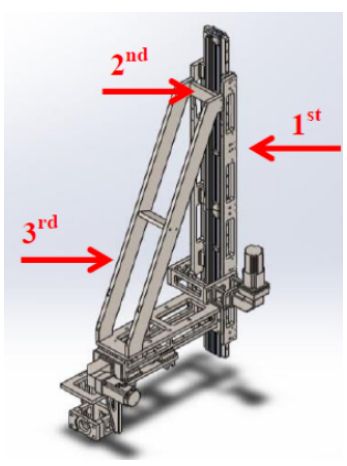

Fig. 6. After four improvement design.

\section{F. Design Improvement}

From analysis result of actual system, the natural frequency in first and second mode need to be improved, so the value will increase. In this case, the part of the system which is need to be improved is the arm of the gantry. There are 4 optional solution to solve this problem, the counter measures will be shown below:

1) The first solution of design improvement is cut the arm of gantry about $400 \mathrm{~mm}$ to shorten the length of the arm because it will reduce the distance between the gripped area by linear guide and the top of the arm, so the moment will decrease $(M=F \times r)$. 
TABLE VI

MANUFACTURE PROCESS COMPARISON OF ACTUAL AND DESIGN IMPROVEMENT

\begin{tabular}{clll}
\hline Solution No. & Cost of Material & $\begin{array}{l}\text { Weight of } \\
\text { System } \\
(\mathrm{Kg})\end{array}$ & $\begin{array}{l}\text { Working } \\
\text { Days }\end{array}$ \\
\hline Actual & - & - & - \\
1 & Rp.30.000,-(4) & $130(4)$ & $1(4)$ \\
2 & Rp.4.174.696,-(3) & $144(3)$ & $6(3)$ \\
3 & Rp.10.841.576,-(2) & $158(2)$ & $8(2)$ \\
4 & Rp.19.066.384,-(1) & $197(1)$ & $11(1)$ \\
\hline
\end{tabular}

2) The second solution of design improvement is make the holder of the arm longer about $400 \mathrm{~mm}$. it will reduce the distance between the gripped area by linear guide and the top of the arm, so the moment will decrease $(M=F \times r)$.

3) The third solution of design improvement is make the holder of the arm longer about $400 \mathrm{~mm}$, then give ribs which connect the holder with the base to reduce the moment in $\mathrm{X}$ direction.

4) The fourth solution of design improvement is make the holder of the arm longer until covering all of the arm itself. Then give ribs which connect the holder with the base to reduce the moment in $\mathrm{X}$ direction.

\section{CONCLUSIONS}

From simulation by using solidworks software and experimental by using accelerometer and gyroscope sensor before, the conclusions will be summarized as (i) the natural frequency of actual system in first and second mode need to be improved, because the value is too low, (ii) the difference between simulation and theoretical result is $0,51 \%$, it means that the simulation result with Solidworks software is valid, (iii) From data acquisition of actual system, the high vibration happen when the arm of gantry is in the lowest position while ungrip the jig from gripper, and when the arm of gantry just starting to move or just stop from moving, (iv) the difference between simulation using solidworks software and experimental using accelerometer gyroscope result is about $3,53 \mathrm{~Hz}$ in $Y$-direction and 2,19 in $X$-direction. The different result happened, because simulation result was not affected by another vibration except the system only (ideal condition), so the result of experimental higher than simulation, and (v) the best design improvement for actual system to increase natural frequency based on simulation result is the first solution, its natural frequency in the first mode increase about 7,0001 Hertz, and in the second mode increase about 13,064 Hertz.

\section{REFERENCES}

[1] Bharath, V.G., 2017, Motion Modeling of Virtual Reality Welding, International Journal of Advance in Scientific Research and Engineering (IJASRE).

[2] Bathe, K.J., 2014, Finite Element Procedures, 2nd Edition, Pretince Hall, New Jersey.

[3] Blevins, R.D., 2001, Formulas for Natural Frequency and Mode Shape, Litton Educational Publishing, United States of America.
[4] Dieter, G.E., \& Schmidt, L.C., 2009, Engineering Design, 4th Edition, McGraw-Hill, New York.

[5] Hibbeler, R.C., 2012, Structural Analysis, 8th Edition, Pretince Hall, New Jersey.

[6] Hubalovsky, S., 2012, Modeling, Simulation, and Visualization of Static Mechanical Properties of Frame of Elevator Cab, International Journal of Mathematical Models and Methods in Applied Science.

[7] Kelly, S.G., 2012, Mechanical Vibration Theory and Application, Cengage Learning, Stamford.

[8] Kumar, V., Singh, K.K., \& Gaurav, S., 2015, Analysis of Natural Frequencies for Cantilever Beam with $I$ - and T-Section Using Ansys, International Research Journal of Engineering and Technology (IRJET).

[9] Kurowski, M.P., 2018, Vibration Analysis with Solidworks Simulation 2018, SDC Publication, United States of America.

[10] Nail, B.G., 2013, Pan \& Tilt Motion Based Gyro Controlled Firing Gun, International Journal of Latest Research in Engineering and Technology (IJLRET).

[11] Rao, S.S., Mechanical Vibrations, 5th Edition, Pretince Hall, New Jersey. 